\title{
Enhancement of Dairy Wastewater Treatment in a Combined Anaerobic Baffled and Biofilm Reactor with Magneto-Active Packing Media
}

\author{
Marta Kisielewska ${ }^{1 *}$, Marcin Dębowski ${ }^{1}$, Marcin Zieliński', Mirosław Krzemieniewski ${ }^{1}$ \\ 1 University of Warmia and Mazury in Olsztyn, Department of Environmental Engineering, ul. Warszawska 117, \\ 10-950 Olsztyn, Poland \\ *Corresponding author's e-mail: jedrzejewska@uwm.edu.pl
}

\begin{abstract}
In this study, a new reactor concept was designed for combining the advantages of anaerobic baffled reactors and biofilm reactors for treating dairy wastewater. The magneto-active microporous packing media manufactured by extrusion technology and modified by the addition of relevant amounts of metal catalysts and magnetic activation were used. The effects of active packing media placing in the different functional areas (hydrolysis or methanogenic) on the reactor performance (organic matter and nutrients removal, biogas production) were studied. The highest biogas production of $337 \mathrm{~L} / \mathrm{d}$ and biogas yield of $415 \mathrm{~mL} / \mathrm{g} \mathrm{COD}_{\text {removed }}$ were achieved when the packing media with magnetic properties were placed in the methanogenic tanks. A stimulatory effect of placing the active packing media in methanogenic tanks on the organic matter removal ( $86 \%$ as COD) and suspended solids elimination from wastewater were noted; however, the magnetic properties did not contribute towards higher organic matter and nutrients removal. Incorporation of metals into the plastic packing media enhanced the phosphorus removal (85-87\%).
\end{abstract}

Keywords: biofilm reactor; compartmentalized reactor design, dairy sewage; magneto-active support medium; biogas; phosphorus removal

\section{INTRODUCTION}

Anaerobic digestion (AD) has been successfully applied in full-scale for the treatment of dairy wastewater (Tiwary et al., 2015). Several bioreactors types have been used; however, the biofilm-based reactors are the most common reactors employed (Rajagopal et al., 2013). Anaerobic dairy wastewater treatment in biofilm reactors has been conducted by using inert carriers such as seashells, plastic materials, ceramic, natural stones, gravel, pumice, sintered glass (Karadag et al. 2015). However, the use of packing media that enhance the sorption, precipitation and the binding of biogenic compounds constitute an alternative to the currently used support materials. Hawkes et al. (1995) used sand and activated carbon as support media for ice-cream wastewater treatment, and activated carbon ex- hibited better performance than sand. Other authors showed that the corrosion of metal elements used as the packing media in an anaerobic reactor enhanced Chemical Oxygen Demand (COD) and phosphorus removal from dairy wastewater (Jędrzejewska-Cicińska, Krzemieniewski, 2010). As a constant magnetic field enhanced the efficiency of dairy wastewater treatment (Zieliński et al. 2014), the magneto-active packing media prepared by coating plastic media with iron and copper powder for dairy wastewater treatment were investigated as well (Dębowski et al. 2014). The authors obtained significantly improved COD removal efficiency, biogas production and methane content in biogas.

The biochemical processes in anaerobic bioreactors are accomplished by the cooperation of four different groups of microorganisms: fermentative, syntrophic, acetogenic, and methanogenic 
bacteria (Venkiteshwaran et al. 2015). The mutualistic behavior of various anaerobic microorganisms results in the decomposition of complex organic substances into simple, chemically stabilized compounds, mainly methane and $\mathrm{CO} 2$. However, each microbial group has different optimal environmental conditions and kinetics (Karadag et al. 2015). In order to provide the optimum conditions for satisfying the requirements of each group of anaerobic microorganisms, a reactor chamber could be divided into compartments (Gulhane et al. 2017). Anaerobic Baffled Reactors (ABRs) consist of alternating hanging and standing baffles, which compartmentalizes the reactor resulting in partial separation of acidogenesis and methanogenesis (Plumb et al. 2001). It has been shown that the compartmentalized design of anaerobic reactor provided a higher resilience to the hydraulic and organic shock loads, higher treatment rate, longer biomass retention times, and lower sludge yields than other anaerobic treatment systems (Reynaud, Buckley 2016).

Combining the advantages of ABF and biofilm reactors, an anaerobic reactor with a vertical labyrinth wastewater flow filled with the magneto-active packing media has been designed. This work aims to study the treatability of dairy wastewater in a new model of reactor and the effects of the active packing media placing in the different functional reactors areas (hydrolysis or methanogenic tank) on the reactor performance (organic matter and nutrients removal, biogas production).

\section{MATERIALS AND METHODS}

\section{Wastewater}

Dairy wastewater was prepared by dissolving 20 g milk powder manufactured by Dairy Plant in Ostrowia Mazowiecka (Poland) per litre of distilled water to achieve the COD concentration of 20,000 $\mathrm{mg} \mathrm{COD} / \mathrm{L}$. The composition of dairy wastewater with a high content of COD was determined according to literature data, where the COD values were varying from 0.1 to $100 \mathrm{~g} / \mathrm{L}$ (Slavov 2017). The dairy wastewater characteristics were as follows: total nitrogen (TN) $620 \pm 29.2 \mathrm{mg} / \mathrm{L}$, ammonia nitrogen (AN) $33 \pm 5.7 \mathrm{mg} / \mathrm{L}$, total phosphorus (TP) $109 \pm 9.2 \mathrm{mg} / \mathrm{L}$, total suspended solids (TSS) $26 \pm 3.6 \mathrm{mg} / \mathrm{L}$.

\section{Biofilm support active media preparation}

The active packing media (APM) used in the experiment were manufactured by microporous extrusion of granulated transparent and plasticised polyvinyl chloride (PVC). PVC, commercially available as Alfavinyl GFM/4-31-TR, was manufactured by Alfa Sp. z o.o. (Poland). Major parameters of the PVC used in the experiment are as follows: density $-1230 \mathrm{~kg} / \mathrm{m}^{3}$, Young's modulus - $2600 \mathrm{MPa}$, tensile strength - $21 \mathrm{MPa}$, elongation at break $-300 \%$, shore A-hardness $80^{\circ} \mathrm{Sh}$. While manufacturing the packing media, PVC was modified by the introduction of $0.8 \% \mathrm{wt}$ granulated blowing agent Hydrocerol 530 (Clariant Masterbatch). Additionally, the PVC was blended with chemically pure copper and iron powder (Cometox). Each time, 5.0\% wt. of metal additives was introduced to PVC used for the production of packing elements. The copper to iron weight ratio was $1_{\mathrm{Cu}}: 9_{\mathrm{Fe}}$ and was set following the previous studies carried out by the authors (data not published). The characteristics of the manufactured APM were as follows: density $-810 \pm 0.6$ $\mathrm{kg} / \mathrm{m}^{3}$, shore A-hardness $-24.8 \pm 0.4^{\circ} \mathrm{Sh}$, tensile strength $-140.5 \pm 2.2 \mathrm{~N}$, porosity $-39.13 \pm 0.4 \%$.

The magnetic properties of the magneto-active packing media (M-APM) were achieved by the introduction of magnets to $40 \%$ of plastic elements placed inside the reactor. The characteristics of the neodymium magnets used in the experiments are as follows: diameter $-10 \pm 0.1 \mathrm{~mm}$, height $-5 \pm 0.1 \mathrm{~mm}$, magnetic flux $\sim 3952 \cdot 10^{-3}$ $\mathrm{mWb}$, magnetic moment $\sim 450.528 \cdot 10^{-6} \mathrm{mWb} \cdot \mathrm{m}$, magnetic field in geometrical center of surface of the magnetic pole with a distance of $0.7 \mathrm{~mm}$ $\sim 0.368 \mathrm{~T}$, magnetic field next to the edge of surface of the magnetic pole (max.) with a distance of $0.7 \mathrm{~mm} \sim 0.384 \mathrm{~T}$, pull force $-0.85 \mathrm{~kg}$.

\section{Experimental research installation setup and operation}

A $100 \mathrm{~L}$ anaerobic reactor with a vertical labyrinth wastewater flow was used in the experiments. The reactor comprised three cylindrical stainless steel containers; that vertical channels and weirs pushed the wastewater through a series of chambers. The influent was pumped to the bottom part of the internal chamber serving as the hydrolysis tank with a working volume of $20 \mathrm{~L}$. The internal recirculation with the yield of $20 \mathrm{~L} / \mathrm{h}$ inside the hydrolysis tank ensured a complete mixing and circulation of the anaerobic sludge 
and wastewater. The outer chambers served as methanogenic tanks with an active volume of $70 \mathrm{~L}$ and downward wastewater flow in the central tank and $10 \mathrm{~L}$ and upward flow in the external. Additionally, the external tank served as the clarification chamber. The temperature in reactor was maintained at $35^{\circ} \mathrm{C}$, the hydraulic retention time (HRT) was 2 days, while the organic loading rate (OLR) was maintained at the level of $10 \mathrm{~g}$ $\mathrm{COD} / \mathrm{L} \cdot \mathrm{d}$. The reactor was initially inoculated at a ratio of $40 \%$ (by volume). The inoculum originated from the closed fermentation tanks of a local municipal wastewater treatment plant. The concentration of volatile solids (VS) seeded into the reactor was $62.7 \%$ total solids (TS).

The experiment was divided into two stages, in which the packing media were placed in the hydrolysis tank $(\mathrm{H})$ or the methanogenic tanks (M). The entire volume of the tanks was filled with the active packing media. In both cases, the experiments were conducted in the two parallel series with the APM (H1 and M1) and with MAPM (H2 and M2), (Fig. 1).

\section{Analytical methods}

The chemical oxygen demand (COD), total nitrogen (TN) and total phosphorus (TP) in dairy wastewater and effluent were analysed once every 24 h using a DR 5000 spectrophotometer (Hach Lange). The content of total solids (TS) and volatile solids (VS) in anaerobic sludge, dairy wastewater and effluent were determined according to the gravimetric method.

The biogas flow rate was measured continuously using a XFM17S digital gas flow meter (Aalborg Instruments \& Controls, Inc., USA). The quality of biogas was analysed using a GMF 430 meter (GasData, England) and a gas chromatograph (GC, 7890A Agilent, USA) equipped with a thermal conductivity detector (TCD). The GC was fitted with the two Hayesep Q columns (80/100 mesh), two molecular sieve columns (60/80 mesh) and Porapak Q column (80/100) operating at a temperature of $70^{\circ} \mathrm{C}$. The temperatures of the injection and detector ports were $150^{\circ} \mathrm{C}$ and $250^{\circ} \mathrm{C}$, respectively. Helium and argon were used as the carrier gases at a flow of $15 \mathrm{~mL} / \mathrm{min}$.

The statistical analysis of results was carried out using the STATISTICA 10.0 PL software package. The hypothesis on the distribution of each analysed variable was verified using the $\mathrm{W}$ Shapiro-Wilk test. One-way analysis of variance (ANOVA) was used to determine the significance of differences between variables. The homogeneity of variance in the groups was analysed using Levene's test. The RIR Tukey test was used to determine the significance of differences between the analysed variables. The statistical significance was adopted at $\mathrm{p}=0.05$.

\section{RESULTS}

\section{Organic matter and nutrients removal}

The study showed that the packing media placement had a significant effect $(p<0.05)$ on the COD removal efficiency from the dairy wastewater (Fig. 2, Fig. 3). When the active packing media were placed in the methanogenic tanks, the COD removal was over $84 \%$, while the effects obtained with the active media placed in the hydrolysis tank did not exceed 79\% (Fig. 2). A similar trend was noted for COD load removal (Fig. 3). The difference between H1/M1 and H2/

\begin{tabular}{|l|l|l|}
\hline \multicolumn{2}{|c|}{ Stage 1 } & \multicolumn{2}{c|}{ Stage 2 } \\
\hline Series 1-H1 & Series 2-H2 & Series 1-M1 \\
\hline
\end{tabular}

Fig. 1. The study organization: H1 - APM placed in the hydrolysis tank, H2 - M-APM placed in the hydrolysis tank, M1 - APM placed in the methanogenesis tanks, M2 - M-APM placed in the methanogenesis tanks 


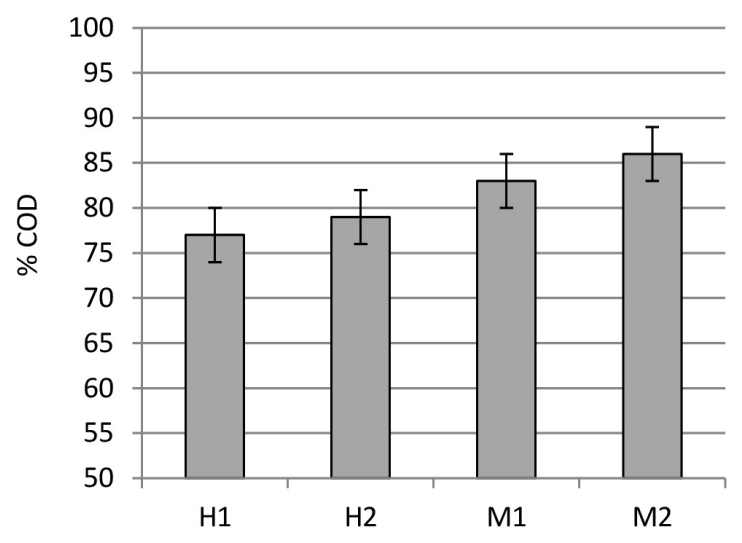

Fig. 2. The effects of active packing media placement and magnetic properties on the COD removal

$\mathrm{M} 2$ was $60 \mathrm{~g} / \mathrm{d}$ and $72 \mathrm{~g} / \mathrm{d}$, respectively ( $<<0.05$ ). The type of the applied medium had no effects on the COD removal ( $>>0.05)$. The use of M-APM in the hydrolysis tank (H2) allowed to remove 791 g COD/d from dairy wastewater, which was only $16 \mathrm{~g} \mathrm{COD} / \mathrm{d}$ higher than using the APM (H1), (Fig. 3). Similarly, using M-APM in the methanogenic tank (M2) allowed to remove $863 \mathrm{~g} \mathrm{COD} / \mathrm{d}$, which was $28 \mathrm{~g} / \mathrm{d}$ more than in M1 ( $>0.05)$.

Neither the type of the active media, nor the placement of the media in anaerobic digester had a significant effect $(\mathrm{p}>0.05)$ on the TN removal. During the study, the TN removal ranged from $22 \%$ in $\mathrm{H} 1$ to $26 \%$ in M2 (Fig. 4). Both active media (APM and M-APM) contributed to a high TP removal ranging from $85 \%$ to $87 \%$ in all series (Fig. 5). However, there were no differences $(p>0.05)$ in the series with different placement of the media in the reactor chamber $(\mathrm{M}$ and $\mathrm{H})$. A slightly higher $(2-3 \%, \mathrm{p}>0.05)$ TP removal was noted in $\mathrm{H} 2$ and M2 series using M-APM. The placement of the active media in methano-

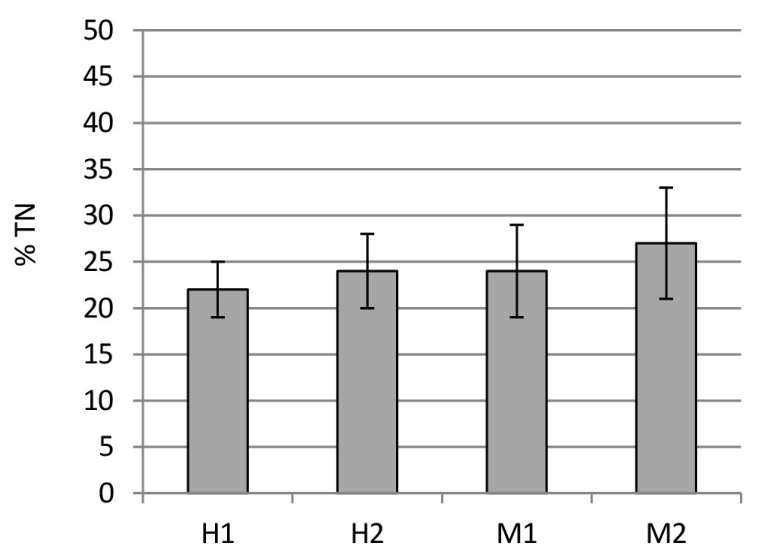

Fig. 4. The effects of active packing media placement and magnetic properties on the TN removal

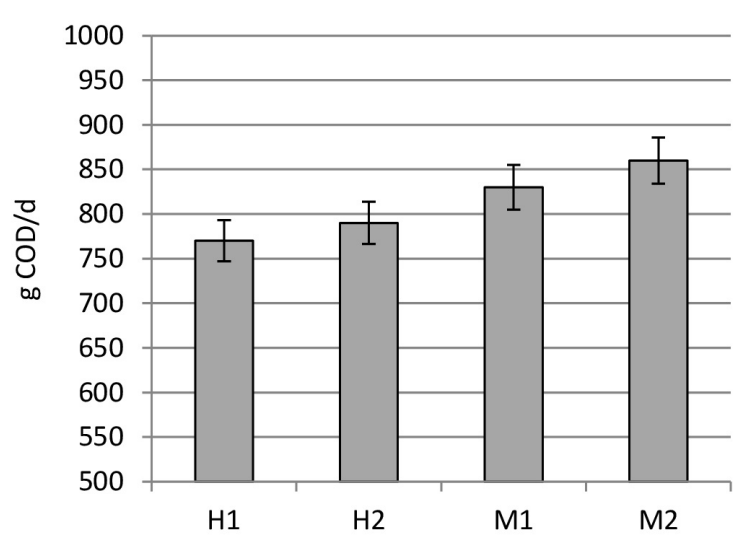

Fig. 3. The effects of active packing media placement and magnetic properties on the COD loading removal

genic tanks affected the concentration of suspended solids in the effluent, which was significantly lower in M1 and M2 series (p<0.05), (Fig. 6). The magnetic properties of M-APM in H-series did not affect $(p>0.05)$ the reduction of the suspended solids in the effluent; however, in the M-series, the differences were significant $(\mathrm{p}<0.05)$, (Fig. 6).

\section{Biogas and methane production}

The magnetic properties of the active packing media contributed towards higher biogas production and biogas yield, both in the H-series and M-series (Fig. 7, Fig. 8). In the M-series, the increase in daily biogas production was about $10 \%$, while in $\mathrm{H}$-series it was $8 \%(\mathrm{p}<0.05)$. Moreover, the placement of the active packing media in methanogenic tanks contributed towards a better biogas production and biogas yield $(\mathrm{p}<0.05)$, (Fig. 7, Fig. 8). The highest biogas production of $337 \mathrm{~L} / \mathrm{d}$ and yield of $415 \mathrm{~mL} / \mathrm{g} \mathrm{COD}_{\text {removed }}$ were achieved in M2. Neither magnetic properties of

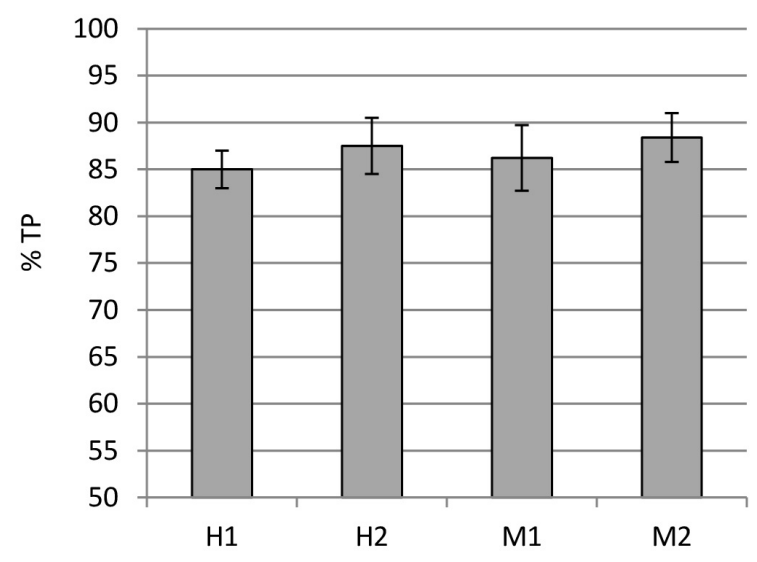

Fig. 5. The effects of active packing media placement and magnetic properties on the TP removal 




Fig. 6. The effects of active packing media placement and magnetic properties on the suspended solids removal

the active media nor their placement did affected the methane content in the biogas ( $p>0.05)$, (Fig. 9). The methane concentration was similar in $\mathrm{H}$-series and $\mathrm{M}$-series, and ranged from $66 \%$ to $67 \%$ during the study (Fig. 9).

\section{DISCUSSION}

A new reactor concept was designed for combining the advantages of ABR and biofilm reactors. Our study results confirmed that the use of the active media in a combined anaerobic baffled and biofilm reactor enhanced the organic matter and phosphorus removal from dairy wastewater, reduced the the suspended solids concentration in the effluent and increased the methane production.

In biofilm reactors, the support materials are responsible for the microbial biomass and suspended solids retention within reactors. The mi-

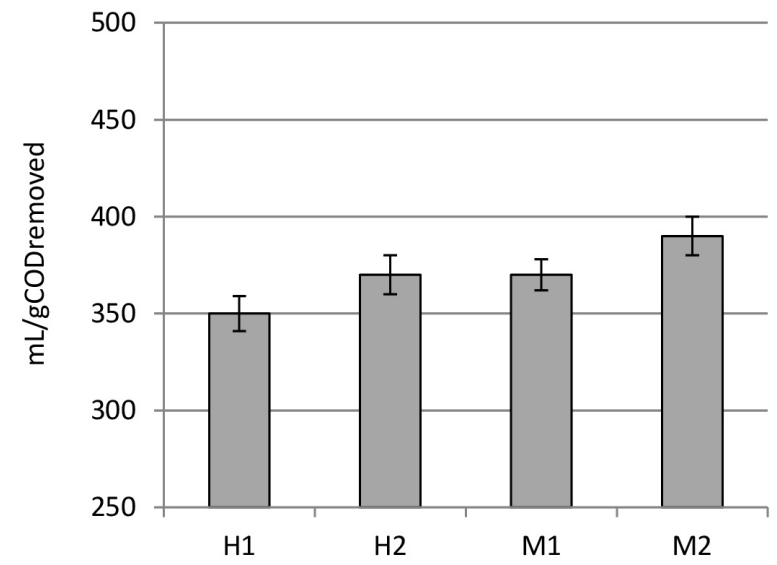

Fig. 8. The effects of active packing media placement and magnetic properties on the biogas yield

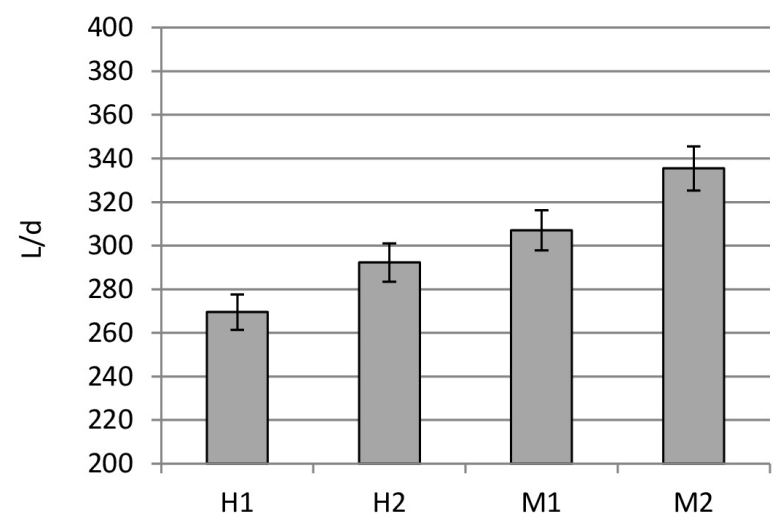

Fig. 7. The effects of active packing media placement and magnetic properties on the daily biogas production

crobial cells concentrations in biofilm reactors can achieve $74 \mathrm{~g} / \mathrm{L}$ by adhering and absorbing of cells to the support material (Qureshi et al. 2005). High biomass concentration contributed to the high treatment performance. In our study, the COD removal efficiency ranged from $77 \%$ to $86 \%$ at OLR of $10 \mathrm{~kg} \mathrm{COD} / \mathrm{m}^{3} \cdot \mathrm{d}$, and the highest COD removal was achieved when the packing media were placed in methanogenic tanks. During the treatment of dairy wastewater, Rajinikanth et al. (2009) obtained 80\% COD removal efficiency at OLR of $17 \mathrm{~kg} \mathrm{COD} / \mathrm{m}^{3} \cdot \mathrm{d}$ in an up-flow anaerobic filter. Kundu et al. (2013) operated an anaerobic fluidized bed reactor for the treatment of simulated milk wastewater. They achieved the COD removal of $78 \%$ at OLR of $8 \mathrm{~kg} \mathrm{COD} / \mathrm{m}^{3} \cdot \mathrm{d}$. In turn, Rodgers et al. (2004) studied whey treatment in anaerobic moving biofilm reactor with plastic support media and obtained 89\% COD removal at OLR of $11.6 \mathrm{~kg} \mathrm{COD} / \mathrm{m}^{3} \cdot \mathrm{d}$.



Fig. 9. The effects of active packing media placement and magnetic properties on the methane concentration in biogas 
The use of packing media that enhance the sorption, precipitation and the binding of biogenic compounds constitutes an alternative to the currently used support materials. In the presented study, an innovative active media with metal additives placed in anaerobic reactors allowed for the effective phosphorus removal (85-87\%) and suspended solids elimination. The corrosion of metals stimulates the biochemical degradation of organic compounds by modification of anaerobic environment inside the reactor through a reduction in the oxidation-reduction potential (ORP) and an increase in the buffer capacity (Zhang et al., 2011; Wu et al., 2015). It also enhances the abiotic processes of contaminant removal, because the formed colloids (i.e. $\mathrm{Fe}(\mathrm{OH})_{2}$ and $\mathrm{Fe}(\mathrm{OH})_{3}$ ) help to eliminate the organic suspended solids in flocculation, adsorption and precipitation reactions (Noubacept, 2008). Moreover, insoluble vivianite compounds are formed in the reaction of metal ions with phosphates, which reduces the phosphorus concentration in the treated wastewater (Shi et al., 2011; Wu et al., 2015). Similar process may favour the nitrogen compounds removal via forming complexes with iron ions. However, during the study, the use of packing media did not enhance the TN removal.

Placing the active media in methanogenic tanks significantly enhanced the COD removal and suspended solids elimination from dairy wastewater. The magnetic properties of the active media did not affect the COD, phosphorus and nitrogen removal, but it enhanced the suspended solids elimination from the effluent. The enhancement of suspended solids coagulation as well as better sedimentation of activated sludge by magnetic field (Zaidi et al. 2014).

According to the literature, the corrosion of metals intensified methanogenesis (Shi et al., 2011; Liu et al., 2015). During the study, the placement of the active packing media in methanogenic tanks significantly enhanced the biogas production and yield. During AD, metal catalysts such as zero-valent iron are electron-donors for methanogenic and denitrifying bacteria (Karri et al. 2005). Under anaerobic conditions, iron corrosion is triggered by gaseous $\mathrm{H}_{2}$, and the formed $\mathrm{CO}_{2}$ is reduced to $\mathrm{CH}_{4}$ by hydrogenotrophic methanogens such as Methanococcus thermolithotrophicus, Methanobacterium thermoautotrophicum, or Methanospirillum hungatei (Wu et al. 2015). Shi et al. (2011) used iron nanoparticles to supplement the UASB reactor and obtained an increase in the biogas productivity and the methane content in biogas (by 12.9-17.9\% and $10.7-12.9 \%$, respectively). In a study on the UASB reactor filled with iron elements Zhang et al. (2011) achieved a $66.8 \%$ content of methane in biogas versus $47.9 \%$ in biogas generated in an UASB reactor without elements.

The magnetic properties of M-APM used in the presented study enhanced the daily biogas production and yield. According to Ji et al. (2010), a suitable level of magnetic induction, not greater than $17.8 \mathrm{mT}$ stimulates the metabolic activity of microorganisms, thus improving the efficiency of wastewater treatment. Zieliński et al. (2014) showed that the value of magnetic induction of $0.38 \mathrm{~T}$ positively affected the organic matter removal and biogas production. Krzemieniewski et al. (2004) applied a stable magnetic field with induction of $0.4-0.6 \mathrm{~T}$ and achieved an increased efficiency of the COD, ammonia nitrogen and orthophosphates removal from municipal, household and dairy wastewater (25-55\%, 50-66\%, 87-90\%, respectively) when compared to the removal rates in the system without magnetic field assistance.

\section{CONCLUSIONS}

This study demonstrated that incorporation of metals into the plastic packing media used in anaerobic reactors could enhance the organic matter, phosphorus and suspended solids removal, and also contributed to a better biogas production. Placing the active packing media in the methanogenic functional areas of an anaerobic reactor significantly enhanced the COD removal form dairy wastewater, suspended solids elimination, as well as the daily biogas production and biogas yield. The magnetic properties of the active media did not affect any COD and phosphorus removal, but it greatly contributed towards higher biogas production and suspended solids elimination.

\section{Acknowledgements}

The research was conducted under Project POIG.01.01.02-14-034/09, entitled: Catalytic fillings for bioreactors for industrial wastewater treatment technology, sponsored by the Programme Innovative Technical Support Systems for Sustainable Development Task IV.5.2. and was also supported by Project No. 18.610.008-300 from the University of Warmia and Mazury in Olsztyn. 


\section{REFERENCES}

1. Dębowski M., Zieliński M., Krzemieniewski M., Brudniak A. 2014. Effect of magneto-active filling on the effectiveness of methane fermentation of dairy wastewaters. International Journal of Green Energy, doi.org/10.1080/15435075.2014.909362.

2. Gulhane M., Pandit P., Khardenavis A., Singh D., Purohit H. 2017. Study of microbial community plasticity for anaerobic digestion of vegetable waste in Anaerobic Baffled Reactor. Renewable Energy, 101, 59-66.

3. Hawkes F.R., Donnelly T., Anderson G.K. 1995. Comparative performance of anaerobic digesters operating on ice-cream wastewater. Water Research, 29, 525-533.

4. Jędrzejewska-Cicińska M., Krzemieniewski M. 2010. Effect of corrosion of steel elements on the treatment of dairy wastewater in a UASB reactor. Environmental Technology, 31, 585-589.

5. Ji Y., Wang Y., Sun J., Yan T., Li J., Zhao T., Yin X., Sun C. 2010. Enhancement of biological treatment of wastewater by magnetic field. Bioresource Technology, 101, 8535-8540.

6. Karadag D., Köroğlu O.E., Ozkaya B., Cakmakci M. 2015. A review on anaerobic biofilm reactors for the treatment of dairy industry wastewater. Process Biochemistry, 50, 262-271.

7. Karri S., Sierra-Alvarez R., Field J.A. 2005. Zero valent iron as an electron-donor for methanogenesis and sulfate reduction in anaerobic sludge. Biotechnology and Bioengineering, 92, 810-819.

8. Krzemieniewski M., Dębowski M., Janczukowicz W., Pesta J. 2004. Effect of the Constant Magnetic Field on the Composition of Dairy Wastewater and Domestic Sewage. Polish Journal of Environmental Studies, 13, 45-53.

9. Kundu K., Bergmann I., Hahnke S., Klocke M., Sharma S., Sreekrishnan T.R. 2013. Carbon source - A strong determinant of microbial community structure and performance of an anaerobic reactor. Journal of Biotechnology, 168, 616-624.

10. Liu Y., Wang Q., Zhang Y., Ni B.J. 2015. Zero valent iron significantly enhances methane production from waste activated sludge by improving biochemical methane potential rather than hydrolysis rate. Scientific Reports, 5, 8263.

11. Noubactep C. 2008. A critical review on the process of contaminant removal in $\mathrm{Fe}^{0}-\mathrm{H}_{2} \mathrm{O}$ systems. Environmental Technology, 29, 909-920.

12. Plumb J.J., Bell J., Stuckey D.C. 2001. Microbial Populations Associated with Treatment of an Industrial Dye Effluent in an Anaerobic Baffled Reactor. Applied and Environmental Microbiology, 67, 3226-3235

13. Qureshi N., Annous B.A., Ezeji T.C., Karcher P., Maddox I.S. 2005. Biofilm reactors for industrial bioconversion processes: employing potential of enhanced reaction rates. Microbial Cell Factories, 4, 24.

14. Rajagopal R., Saady N.M.C., Torrijos M., Thanikal J.V., Hung Y.T. 2013. Sustainable Agro-Food Industrial Wastewater Treatment Using High Rate Anaerobic Process. Water, 5, 292-311.

15. Rajinikanth R., Ganesh R., Escudie R., Mehrotra I., Kumar P., Thanikal J.V., Torrijos M. 2009. High rate anaerobic filter with floating supports for the treatment of effluents from small-scale agro-food industries. Desalination and Water Treatment, 4, 183-190.

16. Reynaud N., Buckley C.A. 2016. The anaerobic baffled reactor (ABR) treating communal wastewater under mesophilic conditions: a review. Water Science Technology, 73, 463-478.

17. Rodgers M., Zhan X.M., Dolan B. 2004. Mixing characteristics and whey wastewater treatment of a novel moving anaerobic biofilm reactor. Journal of Environmental Science and Health Part A: Toxic/ hazardous Substances \& Environmental Engineering, 39, 2183-2193.

18. Shi R., Xu H., Zhang Y. 2011. Enhanced treatment of wastewater from the vitamin $\mathrm{C}$ biosynthesis industry using a UASB reactor supplemented with zero-valent iron. Environmental Technology, 32, 1859-1865.

19. Slavov A.K. 2017. General Characteristics and Treatment Possibilities of Dairy Wastewater - A Review. Food Technology and Biotechnology, 55, 14-28.

20. Tiwary A., Williams I.D., Pant D.C., Kishore V.V.N. 2015. Emerging perspectives on environmental burden minimisation initiatives from anaerobic digestion technologies for community scale biomass valorization. Renewable and Sustainable Energy Reviews, 42, 883-901.

21. Venkiteshwaran K., Bocher B., Maki J., Zitomer D. 2015. Relating Anaerobic Digestion Microbial Community and Process Function. Microbiology Insights, 8, 37-44.

22. Wu D., Zheng S., Ding A., Sun G., Yang M. 2015. Performance of a zero valent iron-based anaerobic system in swine wastewater treatment. Journal of Hazardous Materials, 286, 1-6.

23. Zaidi N.S., Sohaili J., Muda K., Sillanpää M. 2014. Magnetic field application and its potential in water and wastewater treatment systems. Separation \& Purification, 43, 206-240.

24. Zhang Y., Jing Y., Quan X., Liu Y., Onu P. 2011. A Built-In Zero Valent Iron Anaerobic Reactor to Enhance Treatment of Azo Dye Wastewater. Water Science and Technology, 63, 741-746.

25. Zieliński M., Dębowski M., Krzemieniewski M., Dudek M., Grala A. 2014. Effect of the constant magnetic field (CMF) with various values of magnetic induction on the effectiveness of dairy wastewaters treatment under anaerobic conditions. Polish Journal of Environmental Studies, 23, 255-261. 